\title{
Laser Irradiation Effect on the Optical Band Gap of Se-Te-Al Thin Films
}

\author{
Adam A. Bahishti*1, ${ }^{1,}$, Islam Uddin ${ }^{3}$ and M. Zulfequar ${ }^{1}$ \\ ${ }^{1}$ Department of Physics, Jamia Millia Islamia, New Delhi, INDIA \\ ${ }^{2}$ Department of Physics, College of Science Al-Zulfi, Majmaah University (KSA) \\ ${ }^{3}$ Department of Physics, Deanship of educational services, Qassim University (KSA) \\ * Corresponding author email: aabahishti@gmail.com
}

Received: 15 September 2016 / Revised: 27 September 2016 / Accepted: 28 September 2016 / Published: 03 October 2016

\begin{abstract}
Laser irradiation effect on the optical band gap of Se-Te-Al thin films has been studied. Optical data Analysis of thin films indicates indirect allowed transition in the Se-Te-Al system. Analysis of the result reveals that the optical band gap decreases with increasing irradiation time as well as Aluminum content. However, laser irradiation does not show a significant effect at higher Aluminum concentration. It might be due to lack of weak Se-Te bond as Te content decreases with increasing Al content. It shows that alloy with rich $\mathrm{Al}$ content is more stable against laser irradiation. It is also observed that absorption coefficient and extinction coefficient increases with laser irradiation time.
\end{abstract}

Keywords: Laser Irradiation; Chalcogenide alloy; Thin films; Irradiation effect; optical band gap, Se-Te-Al System.

\section{Introduction}

Optical band gap and extinction coefficient are the most significant optical parameter in amorphous semiconductors. Optical absorption measurements are widely used to study disorder and defects and modifications in the density of states upon laser irradiation. The disorder and the defects have a strong influence on the band structure of Chalcogenides. Dependence of thin film composition on optical band gap is well known for the amorphous semiconductors. Recently, there has been an increasing interest in semiconductor thin films due to their exceptional properties, which are remarkably different from those of bulk materials [1-5]. The interest in these materials is principally due to low phonon energy, extended infrared transparency, high refractive index, high photosensitivity, in reversible phase change optical recording etc[1-3]. Se-Te based alloys have created extreme interest due to their greater hardness, higher photosensitivity, higher crystallization temperature, and lower aging effects as compared to the pure amorphous Se [5 -7]. It also has been found that Se-Te based alloys have more advantages than $\mathrm{Se}$ from the technological point of view. Addition of Te into Se improves the corrosion resistance [8]. Therefore, Se-Te based alloys are thought to be promising media and attracted the focus of interest in thin film form because of their properties suitable for device applications [9-11]. These materials are optically non-linear and sensitive to the laser irradiation[3, 12-15]. The absorption of laser irradiation in chalcogenide 
thin film depends strongly on their electronic structure which in turn changes by the interaction with photons. The additional absorption of Te containing chalcogenides are due to the increase in the number of thermally excited free carriers. The most important applications of chalcogenide are now in the field of optics [16-22] and arising mainly from their exhibited infrared transmitting properties [23, 24]. Their potential uses are in integrated optics, optical imaging, optical data storage and infrared optics. Optical recording of information has a leading importance which is a direct consequence of large change in certain physical and chemical parameters of the chalcogenides under the action of light. The energy of the light quanta situated in the UV spectral range is expected to induce some new changes in the Chalcogenides because this energy is equal or higher than the chemical bond energy. The aim of present work is to synthesize amorphous $\mathrm{Se}_{88} \mathrm{Te}_{12-\mathrm{x}} \mathrm{Al}_{\mathrm{x}}$ alloy with different Aluminium concentration and to study the Nitrogen laser irradiation effect on optical band gap of this alloy.

\section{Material and Methods}

Alloys of $\mathrm{Se}_{88} \mathrm{Te}_{12-\mathrm{x}} \mathrm{Al}_{\mathrm{x}}(\mathrm{x}=4,6,8,10)$ have been prepared by melt quenching technique. The high vapour pressure of chalcogenide melts and the tendency, especially at higher temperatures to react with Oxygen requires a closed system under the vacuum condition. Hence, source materials $(99.999 \%)$ having the desired compositional ratio of elements have been sealed in the quartz ampoules under a steady vacuum of $10^{-4}$ torr. The sealed ampoules are kept inside a programmable furnace where the temperature is raised up to $1100 \mathrm{~K}$ at the rate of $4 \mathrm{~K} /$ minute for 10 hours with frequent rocking to ensure the homogenization of the melt. The quenching has been done in ice-cold water. As-quenched alloys have been grounded and the resulting fine powder has been used to prepare the thin films by Physical vapour condensation method. Thin films of prepared alloy of thickness $300 \mathrm{~nm}$ has been deposited on a well cleaned glass substrate in the shape of squares at room temperature and in a vacuum of $\sim 10^{-5}$ torr. Films have been kept inside the deposition chamber under vacuum for
$24 \mathrm{~h}$ to achieve metastable equilibrium. The thickness of the film has been measured under a single-crystal thickness monitor attached with deposition unit. Deposited thin films have been irradiated with a pulsed Transverse Electrical Excitation at Atmospheric pressure (TEA) Nitrogen laser for 5, 10, $15 \& 20$ minutes. Thin film has been placed in a specially designed sample holder as shown in figure 1, which kept at $15 \mathrm{~cm}$ from output laser head.

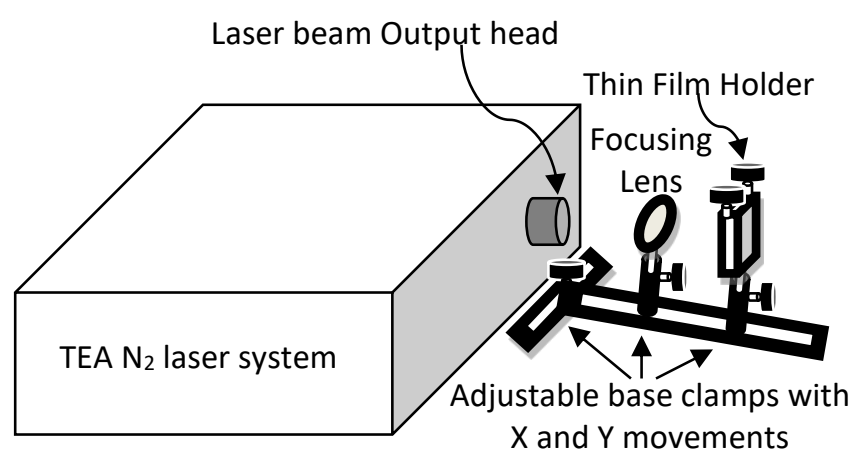

Figure 1: Layout of laser irradiation system

For irradiation a spot of $6 \mathrm{~mm}$ diameter has been adjusted which irradiates thin film with a peak average energy density of $\sim 3.5 \times 10^{5} \mathrm{~W} / \mathrm{cm}^{2}$. A double beam UV/VIS/NIR Scanning Spectrophotometer (Camspec M 550) has been used for optical measurements of the thin films. The optical spectrum has been measured as a function of wavelength (3000-1100 nm) of incident light.

\section{Results}

Measurement of the absorption coefficient $(\alpha)$ as a function of frequency $(v)$ provides a mean to determine the optical band gap $\left(E_{g}\right)$ of thin film. The absorption coefficient has been calculated directly from the following well known relation [25-27]

$$
\alpha=\frac{1}{t} \ln \left(I / I_{O}\right)
$$

where " $t$ " is the film thickness and $\ln \left(I / I_{O}\right)$ corresponds to absorbance, neglecting the reflection coefficient, which is negligible and insignificant near the absorption edge. Estimated value of absorption coefficient $\alpha$ for pristine and laser irradiated samples are given in table 1. 
Table 1: Optical parameter@600 nm for

$\mathrm{Se}_{88} \mathrm{Te}_{12-x} A l_{x}$

\begin{tabular}{|c|c|c|c|c|}
\hline S.N. & $\begin{array}{c}\text { Exposure } \\
\text { time }\end{array}$ & $\alpha\left(10^{4} \mathrm{~cm}^{-1}\right)$ & $\mathbf{k}$ & $\begin{array}{c}\mathbf{E}_{\mathrm{g}} \\
(\mathrm{eV})\end{array}$ \\
\hline $\begin{array}{l}\text { 1. } \\
\text { (a) } \\
\text { (b) } \\
\text { (i) } \\
\text { (ii) } \\
\text { (iii) } \\
\text { (iv) } \\
\end{array}$ & $\begin{array}{l}\text { Ses8 }_{8} \mathbf{T e A l}_{4} \\
\text { Pristine film } \\
\text { Exposure time } \\
5 \mathrm{~min} \\
10 \mathrm{~min} \\
15 \mathrm{~min} \\
20 \mathrm{~min} \\
\end{array}$ & $\begin{array}{l}1.634 \\
1.727 \\
1.758 \\
1.827 \\
\end{array}$ & $\begin{array}{l}0.0804 \\
0.0813 \\
0.0825 \\
0.0855\end{array}$ & $\begin{array}{l}1.59 \\
1.54 \\
1.48 \\
1.39 \\
\end{array}$ \\
\hline $\begin{array}{l}2 . \\
\text { (a) } \\
\text { (b) } \\
\text { (i) } \\
\text { (ii) } \\
\text { (iii) } \\
\text { (iv) }\end{array}$ & $\begin{array}{l}\text { Ses8 }_{\mathbf{2}} \mathbf{T e}_{6} \mathbf{A l}_{\mathbf{6}} \\
\text { Pristine film } \\
\text { Exposure time } \\
5 \mathrm{~min} \\
10 \mathrm{~min} \\
15 \mathrm{~min} \\
20 \mathrm{~min}\end{array}$ & $\begin{array}{l}1.634 \\
1.726 \\
1.737 \\
1.751 \\
2.059 \\
\end{array}$ & $\begin{array}{l}0.0893 \\
0.0894 \\
0.0904 \\
0.0920 \\
0.0936 \\
\end{array}$ & $\begin{array}{l}1.59 \\
1.51 \\
1.44 \\
1.40 \\
1.37\end{array}$ \\
\hline $\begin{array}{l}\text { 3. } \\
\text { (a) } \\
\text { (b) } \\
\text { (i) } \\
\text { (ii) } \\
\text { (iii) } \\
\text { (iv) }\end{array}$ & $\begin{array}{l}\mathbf{S e}_{88} \mathbf{T e}_{4} \mathbf{A l}_{\mathbf{8}} \\
\text { Pristine film } \\
\text { Exposure time } \\
5 \mathrm{~min} \\
10 \mathrm{~min} \\
15 \mathrm{~min} \\
20 \mathrm{~min}\end{array}$ & $\begin{array}{l}1.604 \\
1.659 \\
1.668 \\
1.707 \\
2.051\end{array}$ & $\begin{array}{l}0.0911 \\
0.0953 \\
0.0972 \\
0.0981 \\
0.0999\end{array}$ & $\begin{array}{l}1.56 \\
1.50 \\
1.45 \\
1.40 \\
1.34\end{array}$ \\
\hline $\begin{array}{l}4 . \\
\text { (a) } \\
\text { (b) } \\
\text { (i) } \\
\text { (ii) } \\
\text { (iii) } \\
\text { (iv) }\end{array}$ & $\begin{array}{l}\text { Ses8 }_{\mathbf{T e}} \mathbf{A l}_{10} \\
\text { Pristine film } \\
\text { Exposure time } \\
5 \mathrm{~min} \\
10 \mathrm{~min} \\
15 \mathrm{~min} \\
20 \mathrm{~min}\end{array}$ & $\begin{array}{l}1.674 \\
1.959 \\
1.759 \\
1.827 \\
1.828\end{array}$ & $\begin{array}{l}0.0916 \\
0.0934 \\
0.0936 \\
0.0937 \\
0.0941\end{array}$ & $\begin{array}{l}1.52 \\
1.50 \\
1.47 \\
1.46 \\
1.46\end{array}$ \\
\hline
\end{tabular}

The variation of absorption coefficient $\alpha$ as a function of wavelength $\lambda$ for all pristine thin films has been shown in figure 2 .

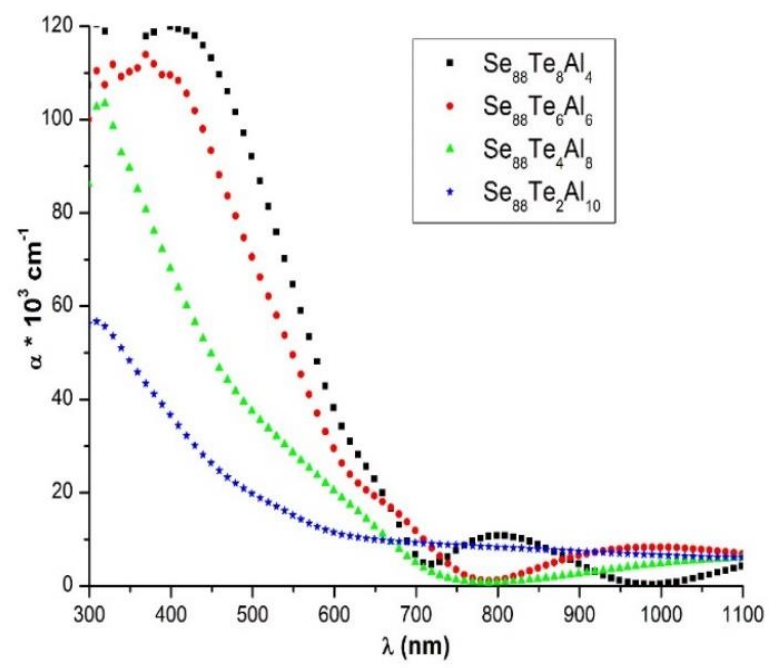

Figure 2: The variation of absorption coefficient a as a function of wavelength $\lambda$ for different $A l$ content.
It is observed that $\alpha$ decreases with increasing $\lambda$ for all samples. For the pristine thin films, Increasing of Aluminum concentration results in reduction of the absorption coefficient $\alpha$ in the range $300-650 \mathrm{~nm}$. In the range $650-1100 \mathrm{~nm}$ the observed peak for $\mathrm{Se}_{88} \mathrm{Te}_{8} \mathrm{Al}_{4}$ at $800 \mathrm{~nm}$ has been disappear by increasing Aluminum concentration.
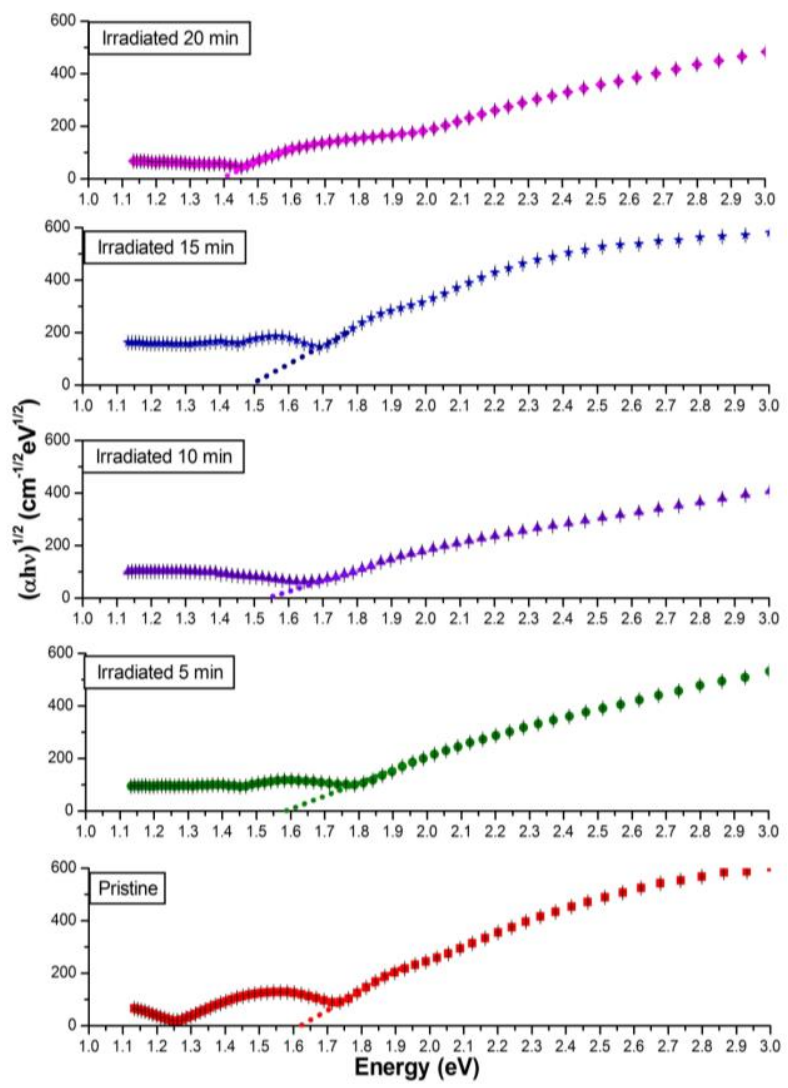

Figure 3: The Variation of $(\alpha h v)^{1 / 2}$ with photon energy (hv) with and without laser irradiation for $\mathrm{Se}_{88} \mathrm{Te}_{8} \mathrm{Al}_{4}$ thin film.

Following expression has been used to calculate optical band gap [28, 29]

$$
\alpha h v=\beta\left(h v-E_{g}\right)^{2}
$$

where $\beta$ is a constant, $E_{g}$ is the optical energy gap of the material. The optical band gap $\left(E_{g}\right)$ has been evaluated from the plot $(\alpha h v)^{1 / 2}$ versus $h v$ by extrapolating the curves to $h v$ axis at $(\alpha h v)^{1 / 2}=0$ and shown in Figures 3-6 for pristine and laser irradiated samples. Optical band gap decreases with increasing laser irradiation time as well as $\mathrm{Al}$ content in alloy and estimated value for all samples are given in table 1 . 
Laser Irradiation Effect on the Optical Band Gap of Se-Te-Al Thin Films
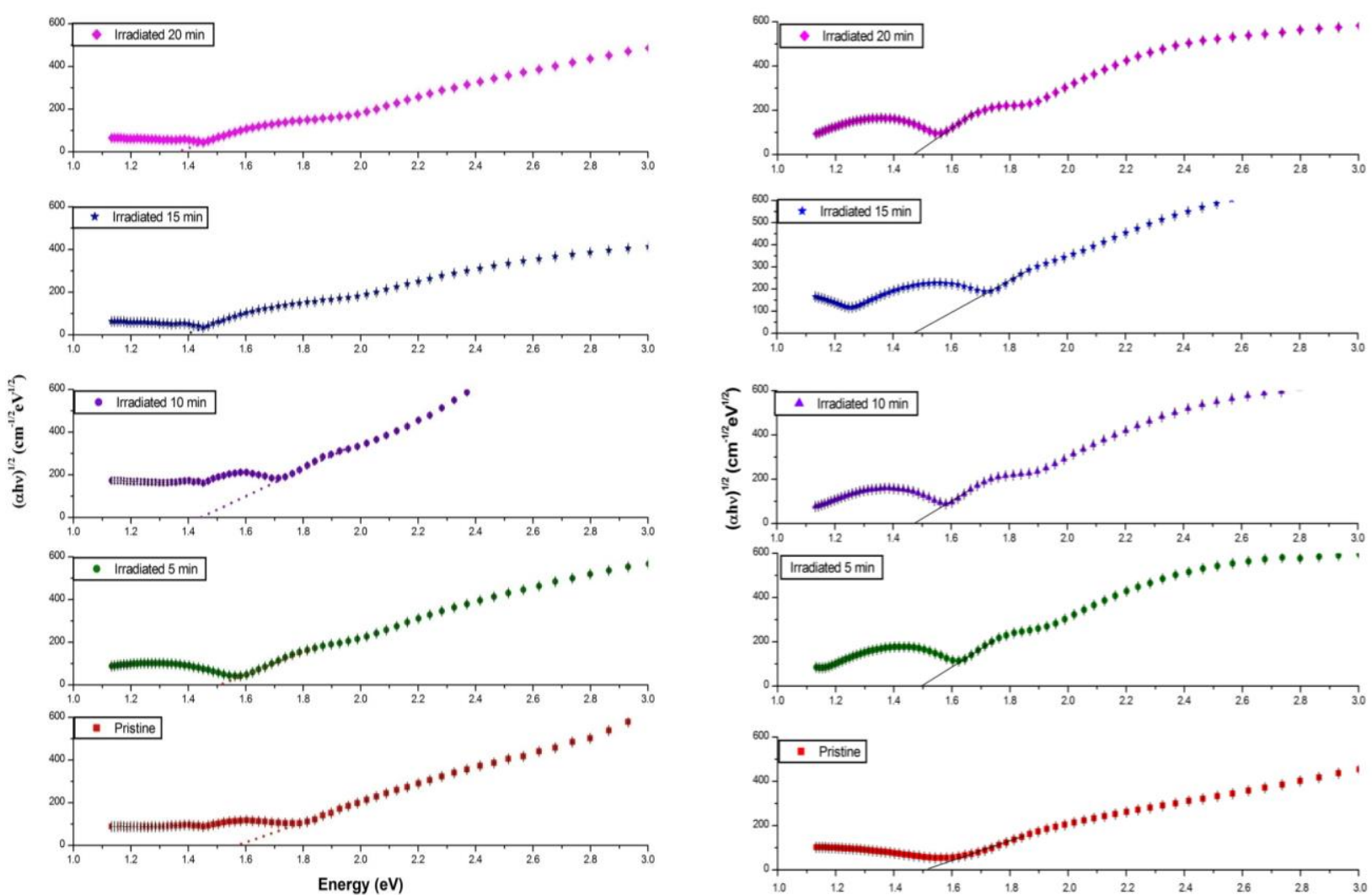

Figure 4: The Variation of $(\alpha h v)^{1 / 2}$ with photon energy $(\mathrm{hv})$ witht and without laser irradiation for $\mathrm{Se}_{88} \mathrm{Te}_{6} \mathrm{Al}_{6}$ thin film.
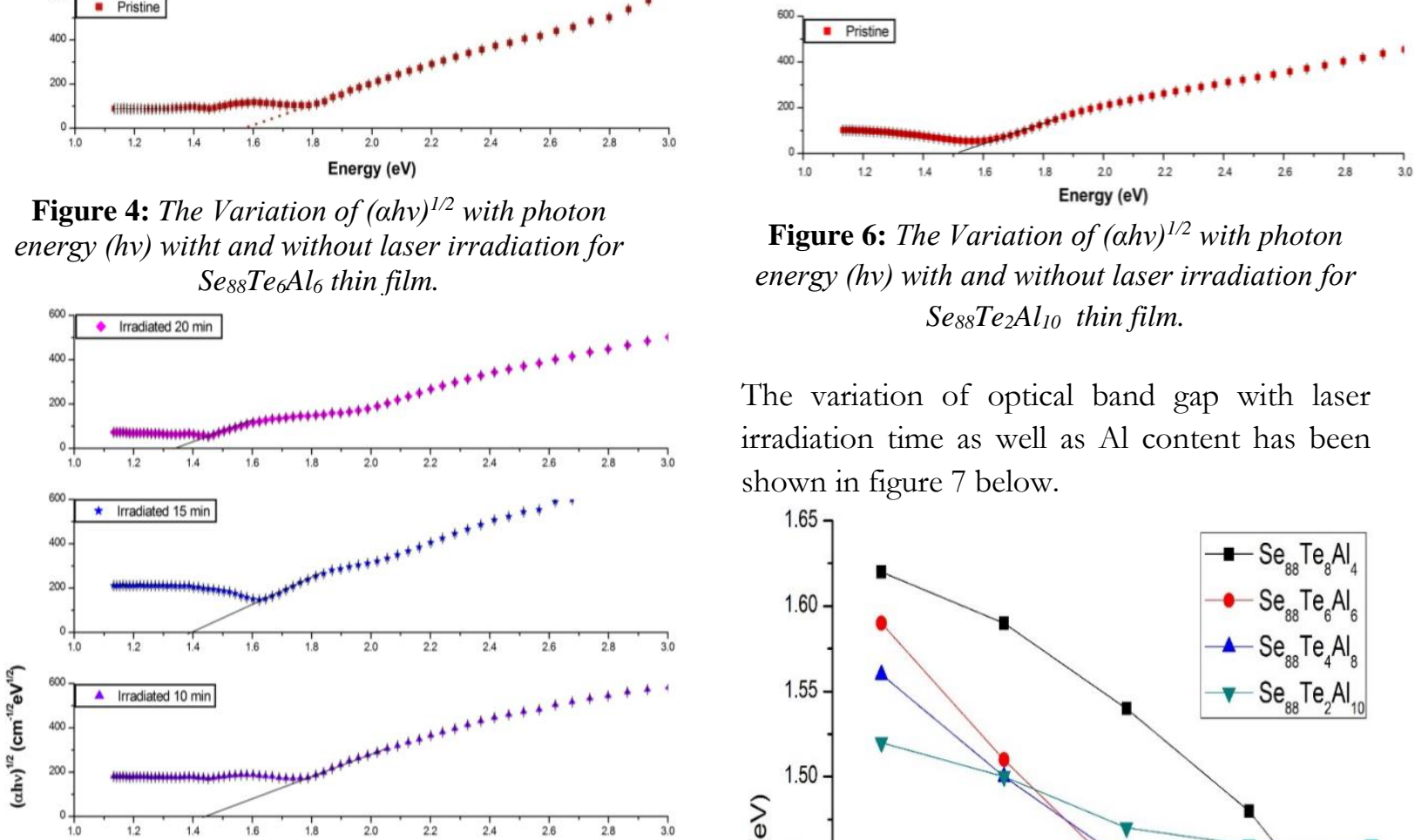

Figure 6: The Variation of $(\alpha h v)^{1 / 2}$ with photon energy (hv) with and without laser irradiation for $\mathrm{Se}_{88} \mathrm{Te}_{2} \mathrm{Al} l_{10}$ thin film.

The variation of optical band gap with laser irradiation time as well as $\mathrm{Al}$ content has been shown in figure 7 below.

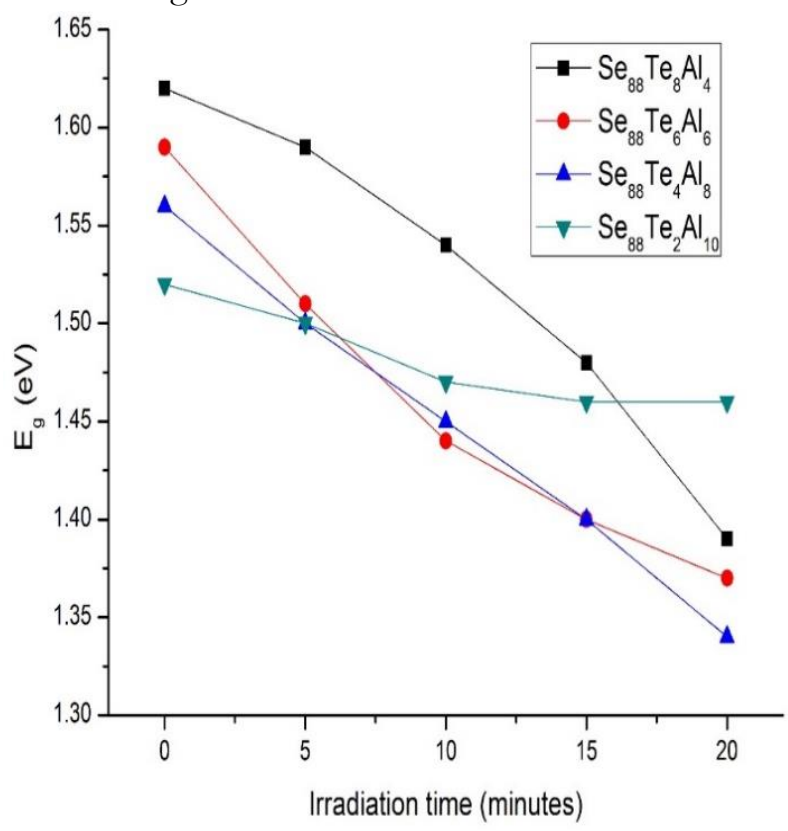

Figure 7: The variation of optical band gap with Irradiation time for different Al content. 
The extinction coefficient $(\mathrm{k})$, which indicates the amount of absorption loss when the electromagnetic wave propagates through the material, has been calculated using well known relation[30, 31]

$$
\mathrm{k}=\frac{\alpha \lambda}{4 \pi}
$$

Where, $\alpha$ is absorption coefficient and $\lambda$ is the corresponding wavelength. In the region of strong absorption, the interference fringes disappear and near the absorption edge reflection coefficient are negligible and insignificant. Hence we choose a wavelength near the absorption edge to analyse the effect of laser irradiation and $\mathrm{Al}$ content on extinction coefficient. The estimated values of the extinction coefficient before and after laser irradiation are given in table 1 , and found to be increases with increasing the laser irradiation time.

\section{Discussion and Conclusion}

The effect of Aluminum concentration on the absorption coefficient $\alpha$ is understandable in terms of structural network. The clusters in $\mathrm{Se}_{88} \mathrm{Te}_{10-\mathrm{x}} \mathrm{Al}_{\mathrm{x}}$ films are almost covered with the metallic additive Aluminum, which results in high reflectance and decrease in the observed absorption coefficient $(\alpha)$. The analysis of optical data shows that the increase in Aluminum concentration results in decreasing the optical band gap which reveals an increase in the band broadening. The decrease in the energy gap can be explained by Kastner's suggestion [32] that, the lone pair electrons adjacent to electropositive atoms will have higher energy than close to electronegative atoms. Therefore, addition of more electropositive atoms to the alloy may raise the energy of some lone pair state and hence to broaden the band into the forbidden gap. $\mathrm{Al}$ is more electropositive than Se and Te, hence an increment of $\mathrm{Al}$ content in $\mathrm{Se}-\mathrm{Te}-\mathrm{Al}$ alloy would expect to raise some lone pair states and broaden the valance band giving rise to additional absorption over a wide range. This may be responsible for the decrease in the optical energy gap by increasing Aluminum content. The estimated optical energy gap decreases with increasing laser irradiation time in $\mathrm{Se}_{88} \mathrm{Te}_{10-\mathrm{x}} \mathrm{Al}_{\mathrm{x}}$ films. This can be attributed to the variation of disorder and defects present in the materials $[8$, 33]. The unsaturated bonds are responsible for the formation of some defects in the films and such defects produces localized states in the band structure which causes in lowering optical band gap. The unsaturated defects produce a large number of unsaturated bonds when get irradiated by laser which increases the density of localized states in the band structure and consequently decreases the optical energy gap $E_{g}$ [34]. Moreover, it is assumed that $1 \mathrm{p}$-electrons as well as s-electrons of covalent bonds located in chalcogens are excited $[3,35,36]$. However, these electronic disturbances are not strongly localized, but decay giving rise to significant atomic displacements within the whole alloys network with a new distribution of bonds. It is more likely that the changes take place in the chains, which means that the bonds within the chains may be broken and rebuilt. Since Se-Te bonds have bond energy less than that of Se-Al bonds, so it is expected that $\mathrm{Se}-\mathrm{Te}$ bonds are more sensitive to laser irradiation. Therefore, upon laser irradiation some of Se-Te bonds are broken leading to the formation of Te-Te homopolar bonds, because of their low energy of formation. This process allows the formation of defects which produce localized states that change the effective Fermi level due to an increase in carrier concentrations. This increase of carriers in localized states will lead to a decrease in the transition probabilities into the extended states, resulting in additional absorption and reduction in the gap [37]. Further, it has been observed that laser irradiation does not show significant effect at higher Aluminum concentration $(10 \%)$. It is reasonable as alloy with a higher content of Aluminum will have less SeTe bond than Se-Al bond and consequently less sensitive to laser irradiation and not easy to create more defect states. It suggests that $\mathrm{Se}-\mathrm{Al}$ bond is stronger and less flexible, and accordingly, can't readily influence by laser irradiation which concludes that alloy with rich $\mathrm{Al}$ content is more stable and $\mathrm{N}_{2}$ laser irradiation can't affect it.

\section{Acknowledgement}

Corresponding author is thankful to the "Council for Scientific and Industrial Research (CSIR), 
India" for providing financial support in the form of senior research fellowship (SRF) to carry out this research work.

\section{How to Cite this Article:}

A. Bahishti, I. Uddin, and M. Zulfequar, "Laser Irradiation Effect on the Optical Band Gap of Se-Te-Al Thin Films", International Annals of Science, vol. 1, no. 1, pp. 8-14, 2016. doi: $10.21467 /$ ias.1.1.8-14

\section{References}

[1] A. Hirohata, J. S. Moodera, and G. P. Berera, "Structural and electrical properties of InSe polycrystalline films and diode fabrication," Thin Solid Films, vol. 510, pp. 247250, Jul 32006.

[2] H. Lee, Y. K. Kim, D. Kim, and D. H. Kang, "Switching behavior of indium selenide-based phase-change memory cell," Ieee Transactions on Magnetics, vol. 41, pp. 1034-1036, Feb 2005.

[3] A. A. Bahishti, I. Uddin, M. Zulfequar, and T. Alharbi, "Laser Irradiation Effect on the Optical Band Gap of Se96-xTe4Hgx Thin Films," Journal of Modern Materials, vol. 1, pp. 17-23, 2016.

[4] A. Zakery and S. R. Elliott, "Optical properties and applications of chalcogenide glasses: a review," Journal of Non-Crystalline Solids, vol. 330, pp. 1-12, Nov 15 2003.

[5] I. Uddin, H. Howari, and G. A. Ansari, "laser irradiation effect on the optical properties of a-Se88Te12-xAlx thin films," Chalcogenide Letters, vol. 13, pp. 117-125, Mar 2016.

[6] R. K. Shukla, S. Swarup, A. Kumar, and A. N. Nigam, "Structural Studies in Glassy Semiconducting Se-Te Alloys," Physica Status Solidi a-Applied Research, vol. 115, pp. K105-K108, Sep 161989.

[7] H. M. Yang, W. Z. Wang, and S. W. Min, "The Effects of as and Te on the Crystallization and Optical Gaps of Selenium," Journal of Non-Crystalline Solids, vol. 80, pp. 503-508, Mar 1986.

[8] A. A. Bahishti, M. A. M. Khan, B. S. Patel, F. S. AlHazmi, and M. Zulfequar, "Effect of laser irradiation on thermal and optical properties of selenium-tellurium alloy," Journal of Non-Crystalline Solids, vol. 355, pp. 2314-2317, Nov 12009.

[9] K. Yilmaz, M. Parlak, and C. Ercelebi, "Space-chargelimited current analysis in amorphous InSe thin films," Journal of Materials Science-Materials in Electronics, vol. 15, pp. 225-229, Apr 2004.

[10] C. Amory, J. C. Bernede, E. Halgand, and S. Marsillac, "Cu(In,Ga)Se-2 films obtained from gamma-In2Se3 thin film," Thin Solid Films, vol. 431, pp. 22-25, May 12003.

[11] A. A. Bahishti, M. A. M. Khan, S. Kumar, M. Husain, and M. Zulfequar, "Effect of laser irradiation on the optical properties of amorphous Se96-xTe4Gax thin films," Chalcogenide Letters, vol. 4, pp. 155-160, Dec 2007.

[12] H. Lu, Y. Q. Tu, X. A. Lin, B. Fang, D. B. Luo, and A. Laaksonen, "Effects of laser irradiation on the structure and optical properties of $\mathrm{ZnO}$ thin films," Materials Letters, vol. 64, pp. 2072-2075, Oct 152010.

[13] A. A. Bahishti, M. Husain, and M. Zulfequar, "Effects of laser irradiation on optical properties of a-Se100-xTex thin films," Radiation Effects and Defects in Solids, vol. 166, pp. 529-536, 2011.

[14] V. Lyubin, M. Klebanov, M. Mitkova, and T. Petkova, "Laser-induced polarization-dependent photocrystallization of amorphous chalcogenide films," Journal of Non-Crystalline Solids, vol. 227, pp. 739-742, 1998.

[15] I. Uddin, "Laser Irradiation Effect on the Optical Properties of $\mathrm{Se}_{88} \mathrm{Te}_{10} \mathrm{Al}_{2}$ Thin Films," American Scientific Research Journal for Engineering, Technology, and Sciences (ASRJETS), vol. 15, pp. 34-39, 2016.

[16] M. Ahmad, J. Kumar, and R. Thangaraj, "Electrical and optical properties of $\mathrm{Sn} 10 \mathrm{Sb} 20-\mathrm{xBixSe} 70(0<=\mathrm{x}<=8)$ glassy films," Journal of Non-Crystalline Solids, vol. 355, pp. 2345-2348, Nov 152009.

[17] J. Orava, T. Kohoutek, T. Wagner, Z. Cerna, M. Vlcek, L. Benes, et al., "Optical and structural properties of GeSe bulk glasses and Ag-Ge-Se thin films," Journal of Non-Crystalline Solids, vol. 355, pp. 1951-1954, Oct 1 2009.

[18] A. Sharma and P. B. Barman, "Calorimetric and optical study of amorphous Se85-xTe15Bix glassy alloy," Thin Solid Films, vol. 517, pp. 3020-3023, Mar 22009.

[19] A. Rabhi, M. Kanzari, and B. Rezig, "Optical and structural properties of CuSbS2 thin films grown by thermal evaporation method," Thin Solid Films, vol. 517, pp. 2477-2480, Feb 22009.

[20] M. Fadel, S. A. Fayek, M. O. Abou-Helal, M. M. Ibrahim, and A. M. Shakra, "Structural and optical properties of $\mathrm{SeGe}$ and $\mathrm{SeGeX}(\mathrm{X}=\mathrm{In}, \mathrm{Sb}$ and $\mathrm{Bi})$ amorphous films," Journal of Alloys and Compounds, vol. 485, pp. 604-609, Oct 192009.

[21] N. Chaudhary, A. A. Bahishti, and M. Zulfequar, "Photoconductivity of Se85-xTe15Hgx thin films," Physica B-Condensed Matter, vol. 407, pp. 2267-2271, Jun 152012

[22] I. Sharma, S. K. Tripathi, and P. B. Barman, "Effect of $\mathrm{Bi}$ addition on the optical behavior of a-Ge-Se-In-Bi thin films," Applied Surface Science, vol. 255, pp. 2791-2795, Dec 302008.

[23] P. Nemec and M. Frumar, "Irreversible photoinduced changes in As48S52 amorphous thin films prepared by pulsed laser deposition," Thin Solid Films, vol. 517, pp. 3635-3638, May 12009.

[24] P. R. de Moura, D. P. Almeida, and J. C. de Lima, "Photo-induced effects in chalcogenide thin films under irradiation by synchrotron light," Journal of Electron Spectroscopy and Related Phenomena, vol. 155, pp. 129135, Mar 2007.

[25] J. Schottmiller, M. Tabak, G. Lucovsky, and A. Ward, "International Conference on Amorphous and Liquid Semiconductors The effects of valency on transport properties in vitreous binary alloys of selenium," Journal of Non-Crystalline Solids, vol. 4, pp. 80-96, 1970/04/01 1970.

[26] E. K. Shokr and M. M. Wakkad, "Optical-Properties of Bi2te2se Thin-Films," Journal of Materials Science, vol. 27, pp. 1197-1201, Mar 11992.

[27] E. D. Mott N, Electronic processes in non-crystalline materials, $2^{\text {nd }}$ ed., 1979.

[28] M. Zanini and J. Tauc, "Temperature-Dependence of Absorption-Edge of Liquid Sulfur," Journal of NonCrystalline Solids, vol. 23, pp. 349-356, 1977. 
[29] E. A. Davis and N. F. Mott, "Conduction in NonCrystalline Systems .5. Conductivity, Optical Absorption and Photoconductivity in Amorphous Semiconductors," Philosophical Magazine, vol. 22, pp. 903-\&, 1970.

[30] S. Chaudhuri, S. K. Biswas, and A. Choudhury, "The Optical-Energy Gap of Thick Amorphous Selenium Film," Journal of Non-Crystalline Solids, vol. 69, pp. 169-170, 1984.

[31] S. R. Elliott, "A Unified Model for Reversible Photostructural Effects in Chalcogenide Glasses," Journal of Non-Crystalline Solids, vol. 81, pp. 71-98, Apr 1986.

[32] M. Kastner, "Bonding Bands, Lone-Pair Bands, and Impurity States in Chalcogenide Semiconductors," Physical Review Letters, vol. 28, pp. 355-\&, 1972.

[33] O. I. Shpotyuk, A. O. Matkovsky, A. P. Kovalsky, and M. M. Vakiv, "Radiation-Induced Changes of Amorphous As2s3 Physical-Properties," Radiation Effects and Defects in Solids, vol. 133, pp. 1-4, 1995.

[34] A. A. El-Fadl, A. S. Soltan, and A. A. Abu-Sehly, "Effect of gamma doses on the optical parameters of Se76Te15Sb9 thin films," Journal of Physics and Chemistry of Solids, vol. 68, pp. 1415-1421, Jul 2007.

[35] R. Y. Golovchak, A. Kozdras, and O. I. Shpotyuk, "Physical ageing in glassy As-Se induced by abovebandgap photoexposure," Solid State Communications, vol. 145, pp. 423-426, Mar 2008.

[36] R. Y. Golovchak, A. Kozdras, C. Gorecki, and O. I. Shpotyuk, "Gamma-irradiation-induced physical ageing in As-Se glasses," Journal of Non-Crystalline Solids, vol. 352, pp. 4960-4963, Nov 152006.

[37] M. M. A. Imran, I. F. Al-Hamarneh, M. I. Awadallah, and M. A. Al-Ewaisi, "Physical ageing in Se94Sn6 glass induced by gamma irradiation," Physica B-Condensed Matter, vol. 403, pp. 2639-2642, Aug 12008.
Publish your research article in AIJR journalsOnline Submission and Tracking Peer-Reviewed Rapid decision Immediate Publication after acceptance Articles freely available online Retain full copyright of your article.

Submit your article at journals.aijr.in

\section{Publish your books with AIJR publisher-}

$\checkmark \quad$ Publish with ISBN and DOI.

$\checkmark$ Publish Thesis/Dissertation as Monograph.

$\checkmark \quad$ Publish Book Monograph.

$\checkmark \quad$ Publish Edited Volume/ Book.

$\checkmark \quad$ Publish Conference Proceedings

$\checkmark \quad$ Retain full copyright of your books.

Submit your manuscript at books.aijr.org 